\title{
DIETER HENRICH, LEITOR DE KANT: SOBRE O FATO LEGITIMADOR NA DEDUÇ̃O TRANSCENDENTAL DAS CATEGORIAS *
}

\author{
Christian Klotz** \\ klotz.chr@googlemail.com \\ Soraya Nour*** \\ nour@cmb.hu-berlin.de
}

RESUMO Este artigo reconstrói os momentos principais dos trabalhos de Dieter Henrich sobre a filosofia teórica de Immanuel Kant. Henrich procura esclarecer e recuperar os fundamentos da teoria do conhecimento de Kant, dos quais seus seguidores teriam se distanciado, a partir da análise da dedução transcendental das categorias. De inicio, Henrich investiga a estrutura da prova na dedução, comparando a primeira e a segunda edição da Crítica da Razão Pura. Em seguida, Henrich investiga no argumento kantiano a relação entre o princípio de identidade da consciência de si, por um lado, e objetividade, por outro. Por fim, estendendo a comparação à Crítica da Razão Prática, Henrich elucida o programa e a metodologia na dedução, mostrando como o "fato" legitimador se torna o elemento fundamental.

Palavras-Chave Immanuel Kant; Dieter Henrich; Dedução Transcendental; Consciência de Si; Objetividade; Fato

* $\quad$ Artigo recebido em junho de 2006 e aprovado em março de 2007.

** Professor do Departamento de Filosofia da Universidade Federal de Santa Maria.

$\star \star \star$ Pesquisadora junto ao Centre Marc Bloch. 
ABSTRACT This article reconstructs the principal moments of Dieter Henrich's work on Immanuel Kant's theoretical philosophy. Henrich tries to clarify and recover the foundations of Kant's theory of knowledge, from which his followers would have taken distance, based on the analysis of the "transcendental deduction of categories". Firstly, Henrich investigates the proof structure in the deduction, comparing the first and the second edition of the Critique of Pure Reason. Secondly, he investigates, inside Kantian argument, the relationship between the identity principle of self-consciousness and objectivity. Finally, extending the comparison to the Critique of Practical Reason, Henrich elucidates the program and methodology of deduction, showing how the legitimating fact becomes the fundamental element.

Key-words Immanuel Kant; Dieter Henrich; Transcendental Deduction; Self-Consciousness; Objectivity; Fact

\section{Introdução}

Em 2004, Dieter Henrich publica Grundlegung aus dem Ich. Untersuchungen zur Vorgeschichte des Idealismus. ${ }^{1} \mathrm{O}$ surgimento desta obra monumental (1.740 páginas) sobre o início do idealismo alemão quando dos 200 anos da morte de Kant, ressalta o autor, é uma mera coincidência. No entanto, esta data é mesmo assim uma ocasião para que Henrich explique os motivos que o levaram a esse estudo. O pensamento de Kant, tantas foram as questões que ele formulou, inspirou na geração que se seguiu uma produção filosófica de riqueza inigualável. No entanto, seus seguidores idealistas, mesmo pretendendo ampliar as conseqüências de seu pensamento, transformaram radicalmente seus princípios fundamentais - um processo que atinge seu ponto culminante com a filosofia de Hegel. A interpretação das obras de Kant tem para Henrich razão histórica e sistemática: trata-se de recuperar os fundamentos do pensamento de Kant, que já para seus primeiros seguidores eram obscuros e que ainda hoje não estão suficientemente esclarecidos. Uma verdadeira "recepção" de Kant ainda está para ser realizada.

$\mathrm{O}$ projeto de Henrich tem seu foco, quanto à filosofia teórica de Kant, na dedução transcendental das categorias, cuja densa argumentação expõe in nuce os fundamentos de sua teoria do conhecimento. Em um artigo de 1989, ${ }^{2}$ 
que expõe a metodologia do argumento kantiano, Henrich analisa a relação entre fato e legitimação, que para Kant não constituíram domínios absolutamente separados. A dedução transcendental da Crítica da Razão Pura, ${ }^{3}$ do mesmo modo que a Crítica da Razão Prática, ${ }^{4}$ remete a um fato. A dedução não é definida como cadeia de silogismos, mas, tal como uma peça jurídica, sua "prova" consiste na referência a um fato legitimador. Com efeito, elucida Henrich, se hoje chamamos de "dedução" apenas uma cadeia de silogismos (nesse sentido tendemos a interpretar a dedução de Kant), no século XVIII "dedução" era o nome de um instrumento jurídico, no qual a "prova" partia de um "fato". É de acordo com este modelo jurídico que Kant elaborou as deduções transcendentais tanto na Crítica da Razão Pura como na Crítica da Razão Prática.

Este artigo reconstrói o percurso de Henrich em sua análise da dedução transcendental de Kant a partir de três de seus textos, que abrangem os resultados de quase duas décadas de suas pesquisas: "Die Beweisstruktur von Kants Transzendentaler Deduktion" (1973), Identität und Objektivität (1976) e "Kant's Notion of a Deduction and the Methodological Background of the First Critique" (1989). No primeiro, Henrich investiga a estrutura da prova na dedução, comparando a primeira e a segunda edição da Crítica da Razão Pura. A dedução é aqui considerada ainda uma cadeia de silogismos. No segundo, Henrich investiga no argumento kantiano a relação entre o princípio de identidade da consciência de si, por um lado, e objetividade, por outro. Por fim, o terceiro texto, estendendo a comparação à Crítica da Razão Prática, elucida o programa e a metodologia na dedução, mostrando como a questão do "fato" se torna fundamental, ao mesmo tempo em que retifica a interpretação da dedução como uma cadeia de silogismos.

\section{A estrutura da dedução transcendental das categorias}

Henrich analisa a relação lógica entre os passos parciais da dedução das categorias em seu artigo sobre a estrutura da prova da dedução transcendental, ${ }^{5}$ no qual compara a estrutura da prova na primeira e na segunda edição da primeira Crítica a fim de mostrar porque apenas nesta última o argumento estaria plenamente desenvolvido. 
A tarefa da dedução é mostrar que as categorias do entendimento são $a$ priori válidas para todos os objetos da experiência, limitando ao mesmo tempo o uso teórico das categorias à esfera dos objetos empíricos. Na segunda edição da Crítica, sua conclusão parece ser traçada duas vezes em duas passagens completamente diferentes. A conclusão da seção 20 não parece diferir do resultado da seção 26. Na seção 20, Kant conclui que "a multiplicidade em uma intuição dada é necessariamente sujeita às categorias" (B 143). Já na seção 26, sua conclusão é de que "as categorias (...) são (...) válidas a priori para todos os objetos da experiência" (B 161).

Contudo, interpretar as conclusões das seções 20 e 26 como duas provas da mesma proposição levaria a um conflito com a seção 21, na qual Kant afirma que aqueles dois argumentos, antes que duas provas, constituem juntos a prova da dedução: "Na proposição acima inicia-se a dedução dos puros conceitos (...). No que se segue $(\S 26)$... o propósito da dedução será completamente atingido" (B 144/145). As seções 20 e 26, portanto, oferecem dois argumentos com resultados significativamente diferentes, que conduzem juntos a uma única prova da dedução transcendental, o que será chamado pelo autor de "prova em dois passos". Henrich examina então duas propostas baseadas na teoria da dupla-prova: ${ }^{6}$ segundo Adickes/Paton ${ }^{7}$ e segundo Erdmann/de Vleeschauwer. ${ }^{8}$

Adickes e Paton referem-se à distinção, estabelecida por Kant na primeira edição da Crítica, entre "dedução subjetiva" e "dedução objetiva". No Prefácio desta edição, Kant distingue dois aspectos da dedução transcendental: o aspecto objetivo, que torna inteligível a validade das categorias, isto é, a demonstração de que as categorias têm validade; o aspecto subjetivo, que investiga a relação das categorias com as faculdades de conhecimento, isto é, a demonstração de como as categorias adquirem validade. Para Adickes e Paton, a prova da validade objetiva é dada pela seção 20, e a demonstração das condições subjetivas de aplicação pela seção 26. Para Henrich, contudo, a distinção introduzida na primeira edição da Crítica não se aplica à segunda versão da dedução, onde na seção 21 Kant afirma que a demonstração da validade objetiva das categorias será completada na seção 26.

Erdmann e de Vleeschauwer, por sua vez, consideram dois tipos de demonstração estabelecidos na primeira versão da dedução: a que parte "de cima", ou seja, da consciência de si, e a que parte "de baixo", ou seja, das 
representações sensíveis. Os autores aplicam essa distinção para o argumento da segunda edição: a seção 20 corresponderia à dedução "de cima" e a seção 26 à dedução "de baixo". Tal proposta, observa Henrich, está em acordo com a seção 26, mas não com a seção 20, porque ambos os argumentos partem da intuição para mostrar que esta pode se tornar uma representação unitária apenas quando as funções intelectuais são aplicadas a ela.

Henrich propõe uma outra solução a partir das proposições das seções 20, 21 e 26. Na seção 20, Kant afirma que as intuições estão submetidas às categorias na medida em que elas possuem unidade (B 143). Tal restrição (já possuir unidade) é indicada por Kant pela letra maiúscula do artigo indefinido na expressão "em Uma intuição" (in Einer Anschauung). Isso não foi compreendido por Norman Kemp Smith para quem essa expressão significa que uma única intuição é sujeita às categorias. ${ }^{9}$ Contudo, como em alemão o pronome indefinido ein e a palavra unidade - Einheit - têm a mesma raiz, Kant pode expressar pela letra maiúscula não a distinção de qualquer intuição arbitrária oposta às outras (singularidade), mas sua unidade interna. Então, conclui Henrich, o resultado da seção 20 é válido para intuições na medida em que elas contêm unidade. Onde há unidade da intuição, diz Henrich, esta pode ser pensada de acordo com as categorias. ${ }^{10}$

A seção 21 anuncia que a restrição da seção 20 será superada na seção 26, que mostra que as categorias são válidas "para todos os objetos de nossos sentidos” (B 161). Segundo Henrich, a função deste passo é intrinsecamente ligada ao dualismo de entendimento e sensibilidade em Kant. Com efeito,

tudo de que podemos nos tornar conscientes torna-se acessível a nós por meios que não dependem imediatamente desta consciência. De acordo com Kant, é por esta razão que a consciência deve ser entendida como uma atividade, que está sempre tornando-se consciência, e cuja unidade necessária interna nos leva a lhe dar o nome de "eu". Mas isto sempre pressupõe que algo está presente em primeiro lugar que deve se tornar consciente. Então nossa consciência pode ser encontrada apenas junto com uma faculdade "passiva", receptiva, que é distinta e, em certos aspectos, oposta à espontaneidade da consciência. ${ }^{11}$

Essa referência, essencial para o entendimento, a representações dadas na sensibilidade como uma faculdade irredutivelmente diferente, é a raiz do problema ao qual se refere o segundo passo da dedução. O primeiro passo mostrou que todas as intuições unificadas na consciência estão submetidas às 
categorias como princípios da sua unidade. No entanto, questiona-se se todas as representações dadas na sensibilidade podem ser unificadas. $\mathrm{O}$ primeiro passo ainda permite que a possibilidade de unificar se limite a uma parte das intuições dadas. O segundo passo, argumenta Henrich, tem a tarefa de excluir a possibilidade de tal desproporção entre consciência e sensibilidade e, assim, de mostrar que não só as intuições, na medida em que possuem unidade, mas todas as intuições estão submetidas às categorias.

$\mathrm{O}$ fato de o segundo passo tratar essencialmente de um problema que surge da diferença entre entendimento e sensibilidade explica, segundo Henrich, porque Kant volta-se então para os resultados da Estética Transcendental, enfatizando a tese de que tempo e espaço são intuições puras que constituem, ao mesmo tempo, condições formais de todas as intuições empíricas (cf. B 160). Kant emprega essa concepção no segundo passo da dedução para destacar que tempo e espaço são intuições que possuem unidade; conseqüentemente, a unidade deles deve ser concebida de acordo com o resultado do primeiro passo da dedução, isto é: como uma unidade que está de acordo com as categorias. Assim, tempo e espaço, nos quais todas as intuições sensíveis são dadas, são unidades estruturadas de acordo com as categorias. Todos os dados sensíveis como tais, em virtude da unidade de tempo e espaço, estão submetidos à condição de estar de acordo com a unidade exigida pelo entendimento (cf. B 160).

Henrich enfatiza que o argumento da dedução na sua reconstrução refere-se essencialmente ao entendimento e à sensibilidade como faculdades irredutíveis e cooperativas. Isso mostra que a segunda dedução está em completo acordo não só com a estrutura da primeira Crítica, mas também com a concepção kantiana de sistema. ${ }^{12}$ Kant baseia a filosofia transcendental no princípio unificador da unidade da consciência de si como "o ponto mais alto" (B 134), mas por uma maneira de argumentar muito peculiar ("kantiana", diz Henrich) ele combina ao mesmo tempo proposições que expressam os princípios de faculdades irredutivelmente diferentes. Deve haver um princípio unificador que permita que se compreenda o entendimento e tal princípio não deve excluir o outro; deve-se considerar a diferença essencial nas raízes de nosso conhecimento e tornar possível um raciocínio que estabelece sua síntese. Essa concepção é diferente tanto do empirismo - que não tem qualquer princípio $a$ priori de unidade - como do idealismo especulativo, que não tem uma unidade 
essencial de elementos originariamente distintos. A dedução transcendental de Kant - mas só na segunda versão, ressalta Henrich - contém tal conceito.

\section{Identidade e objetividade}

\section{Objetividade}

Após ter analisado a estrutura da dedução, Henrich pode então tratar em sua obra Identität und Objektivität (1976) do vínculo que a dedução pretende estabelecer entre o princípio da identidade da consciência de si e a objetividade. ${ }^{13} \mathrm{~A}$ dedução das categorias exige a análise de características do "eu penso" que não estão em foco quando se discute a noção geral de reflexão: seu estatuto quase cartesiano e sua relação com a verdade e a forma da proposição enquanto tal. Henrich coloca em foco uma tese que é característica para a teoria do conhecimento de Kant: só conhecemos objetos da experiência se para toda experiência usamos conceitos e pressupomos princípios que não são derivados da experiência, mas que se fundam na constituição da consciência de si, chamada de "unidade transcendental da apercepção".

Duas objeções foram feitas a Kant. A primeira objeção contesta que nosso conhecimento de objetos da experiência tenha pressupostos nãoempíricos. A segunda objeção contesta que pressupostos apriorísticos de nosso conhecimento, uma vez admitidos, sejam explicados pela consciência de si. No entanto, pode-se encontrar argumentos que respondam a essas duas objeções na doutrina kantiana da objetividade bem como em sua doutrina da consciência de si como um princípio de identidade.

A exposição de Henrich parte da investigação kantiana das condições de objetividade, ${ }^{14}$ e, conforme nos diz, esta já fornece resultados suficientes para refutar a teoria empirista do conhecimento. Além disso, a argumentação kantiana que parte da consciência de si, por sua vez, deve recorrer à análise do conceito de objetividade. No entanto, a discussão da análise kantiana de objetividade mostra também que esta não é suficiente para os propósitos da dedução das categorias, sendo, por isso, necessário para Kant voltar-se para a consciência de si como princípio supremo de sua argumentação.

De acordo com a epistemologia dominante no seu tempo, a investigação kantiana das condições de objetividade pressupõe que os dados básicos de todo nosso conhecimento da realidade são "sensações" - apresentações de 
qualidades simples em um conjunto difuso no espaço. No entanto, ainda que o conhecimento de objetos seja possível só por meio de tais dados, uma análise elementar do conceito de objeto mostra que a referência a objetos envolve uma dimensão diferente. $\mathrm{O}$ conceito de objeto inclui condições de constância que as sensações não têm; em particular, um objeto pode continuar o mesmo, enquanto que os dados que o apresentam são alterados. Além disso, a referência a objetos exige mais do que apenas a consciência de apresentações: ela visa à objetividade, distinguindo representações verídicas de "meras" representações. No entanto, para fazer essa distinção, o sujeito só pode usar os dados simples que, por si, ainda não apresentam objetos. Por consequiência, as relações entre esses dados - sua coerência ou unidade - devem ser o aspecto constitutivo para uma representação de um objeto, em contraste com uma "mera" representação. Como os dados sensíveis por si mesmos não podem fornecer a consciência da sua unidade, esta deve surgir de uma atividade do sujeito cognoscente. Com isso, a tese kantiana de que a "síntese" exercida pelo sujeito constitui a referência a objetos resulta de uma análise do conceito de objeto.

No entanto, esse resultado ainda é compatível com a noção de que a síntese depende de regularidades observadas empiricamente e, com isso, segue regras contingentes. A tese - essencial para a posição kantiana - de que a síntese que se refere a objetos exige regras a priori justifica-se por outro aspecto de objetividade: a referência a objetos é exercida essencialmente em juízos. Então, pode-se esperar que uma consideração das condições estruturais do juízo mostrará que a objetividade exige certas regras a priori às quais os dados estão submetidos. Por isso, a referência à forma do juízo é um elemento central na análise kantiana de objetividade. Aqui, a questão de Kant é que um juízo categórico envolve essencialmente a ligação de um conceito sujeito com um conceito predicado. Isso parece já implicar que um juízo envolve a "síntese" de dois aspectos ou propriedades do objeto de acordo com uma regra a priori que corresponde à forma da ligação dos conceitos. No entanto, como Henrich argumenta, não há um caminho tão direto da forma do juízo para a concepção kantiana da síntese. Pois um juízo categórico pode envolver um demonstrativo que se refere a uma qualidade simples, um "quale" (por exemplo: "Isso é um verde"). Neste caso, não há um conteúdo descritivo que corresponda ao termo sujeito; conseqüentemente, o juízo não envolve uma síntese de aspectos ou propriedades distintos do objeto. Todo o conteúdo do conhecimento está contido no predicado. Por permitir tais juízos, a forma do juízo categórico por si não implica a necessidade da síntese. 
Contudo, segundo Henrich deve-se também dizer que juízos com referência demonstrativa a "qualia" são casos muito particulares do uso da forma do juízo categórico. ${ }^{15}$ No uso normal dessa forma, o predicado não esgota toda a concepção do objeto que o sujeito possui. Em vez disso, há uma concepção do objeto que difere do conceito predicado e que é expressa pelo termo sujeito do juízo. Por isso, no uso normal da forma do juízo sujeitopredicado, a negação de uma predicação expressa pelo juízo não aniquila toda a nossa concepção do objeto. Além disso, um juízo categórico implica tipicamente a possibilidade de uma conjunção de juízos sobre o mesmo objeto envolvendo predicados diferentes do predicado contido nesse juízo. Então, o uso normal da forma do juízo sujeito-predicado está vinculado a operações lógicas, de tal modo que ele só pode cumprir sua função se o objeto se caracteriza diversamente do predicado. Assim, não a mera forma do juízo categórico, mas o uso que se faz desta forma implica a complexidade do objeto e, com isso, a necessidade da "síntese" para a referência a objetos. Além disso, esse resultado envolve uma regra especifica da síntese como condição a priori de qualquer conhecimento objetivo: objetos devem ser concebidos como algo que possui uma pluralidade de propriedades e como unidade de diversos predicados. Segundo Henrich, esse ponto se expressa mais claramente numa reflexão de Kant escrita provavelmente em 1797 (n. 6.350); nessa reflexão, Kant explicitamente vincula sua teoria da síntese à análise do uso da forma do juízo sujeito-predicado. ${ }^{16}$

A reconstrução da análise kantiana da objetividade estabelece um resultado importante para a dedução transcendental das categorias. Ela mostra que a objetividade, por usar a forma do juízo categórico, exige uma síntese dos dados de acordo com uma regra que é uma condição necessária de nosso uso desta forma. No entanto, isso mostra também o limite da análise da objetividade como estratégia para a dedução das categorias: a análise de objetividade só pode estabelecer que nosso conhecimento de objetos exige uma síntese de acordo com regras a priori. No entanto, esse resultado não esclarece em que âmbito um conhecimento de objetos é possível. Então, a análise de objetividade não exclui a possibilidade de que a referência a objetos se limite a certas ocasiões, ou seja, a possibilidade de uma consciência desintegrada que não pode incorporar todas as suas experiências no conhecimento de um mundo objetivo. No entanto, é essencial para o projeto kantiano da dedução transcendental das categorias mostrar que o uso das categorias é necessário 
para todas as experiências conscientes que, consequientemente, fazem parte do conhecimento de um mundo objetivo. Para mostrar isso, argumenta Henrich, tornou-se necessário para Kant basear a dedução das categorias não na análise de objetividade, mas na consideração da consciência de si e de sua identidade.

\section{Identidade da consciência de si}

Um aspecto da consciência de si é que ela é simples. Quando me penso como sujeito pensante de meu pensamento, o "eu" nesses pensamentos significa apenas que um pensador está ligado de uma única e mesma maneira a todos seus pensamentos. Assim, a consciência "eu" por si ainda não envolve as diversas propriedades do si-mesmo como pessoa; ela é "simples" no sentido de que ela não exibe nenhuma complexidade ou pluralidade interna. Ao mesmo tempo, o sujeito consciente relaciona-se aos diversos conteúdos do seu pensamento. Então, uma característica da subjetividade é: ser simples e ao mesmo tempo referir-se à multiplicidade. A consequiência é que nossa consciência de si deve ser um princípio de unidade (Einheitsprinzip): todos os pensamentos dos quais um pensador é consciente como "seus" pensamentos pertencem de uma única maneira a ele como sujeito simples.

No entanto, segundo Henrich a unidade dos pensamentos, conseqüência da simplicidade, ainda não demonstra suficientemente uma tese essencial para a dedução transcendental das categorias: a unidade dos conteúdos conscientes que um sujeito tem deve estar de acordo com regras que o sujeito conhece $a$ priori. A unidade dada com a simplicidade significa, em primeiro lugar, que os conteúdos têm algo em comum, a saber, pertencem ao mesmo sujeito simples. Esse fato ainda não inclui relações entre esses conteúdos estabelecidas pela síntese. Então, um argumento que parte da simplicidade deveria mostrar que para possuírem a unidade implicada pela simplicidade do eu, os conteúdos devem ser unificados mediante uma atividade sintética exercida de acordo com regras. Segundo Henrich, tal argumentação é possível. Mas ela só mostraria que deve haver uma síntese segundo regras à qual os conteúdos devem ser submetidos antes de ser conscientes. Isso seria uma condição para que possamos nos tornar conscientes dos conteúdos. Não se poderia afirmar que as regras de tal síntese pré-consciente devem ser conhecidas do sujeito, ou até ser conhecidas a priori. Elas seriam apenas postuladas do ponto de vista filosófico. Contudo, Kant quer mostrar que a consciência de si envolve um conhecimento a priori de regras da síntese. Por isso, argumenta Henrich, é necessário basear o argumento da dedução das categorias num outro aspecto do que na simplicidade da consciência de si - num aspecto que Kant, na sua 
crítica dos paralogismos da psicologia racional, explicitamente distingue da simplicidade: a identidade do "eu penso". ${ }^{17}$

No trecho que Henrich considera como a passagem chave para a interpretação da dedução transcendental, Kant afirma que o sujeito "não poderia pensar a priori sua própria identidade no diverso das representações" se ele não tivesse "diante de seus olhos" a regra a priori segundo a qual ele unifica todas as suas representações (A 108). Para Henrich, é a "identidade numérica" da consciência de si que Kant considera aqui - ela possibilita atingir o que em relação a sua simplicidade é inatingível. No entanto, para entender o argumento reconstruído por Henrich, é preciso investigar variantes de definições da identidade numérica da consciência de si. Foi Leibniz quem introduziu o conceito "estrito" de identidade numérica. Segundo esse conceito, objetos são numericamente idênticos se eles possuem exatamente as mesmas propriedades. Exclui-se a possibilidade da alteração, ou seja, a possibilidade de um objeto percorrer estados nos quais ele possui propriedades diferentes, permanecendo um objeto numericamente idêntico. A concepção leibniziana da substância como mônada, na qual todas as suas propriedades são presentes de início, é uma consequiência deste conceito. Já Crusius tinha criticado o conceito de identidade numérica, objetando que uma coisa singular pode permanecer a mesma na troca de seus estados, na medida em que as propriedades constitutivas dessa coisa permanecem inalteradas. Este é o conceito "moderado" de identidade numérica. Segundo ele, a identidade de um objeto mantém-se no percorrer dos estados diferentes nos quais ele exibe propriedades diferentes.

Segundo Henrich, é o conceito moderado de identidade numérica, no qual se baseia a concepção da "identidade da apercepção", que Kant introduz na dedução das categorias. Como se sabe, Kant rejeita o conceito estrito de identidade numérica no qual a metafísica de Leibiniz se funda. Além disso, argumenta Henrich, existem argumentos especificamente relacionados à consciência de si para favorecer o conceito de identidade moderado no argumento da dedução das categorias. Pois a reflexão, pela qual a consciência "eu penso" acrescenta-se a uma representação, deve ser concebida como uma ação do sujeito que altera o seu estado representacional - há uma diferença entre um estado no qual o sujeito meramente representa e o estado no qual o sujeito refere-se a uma representação como sendo "sua", refletivamente. No entanto, a alteração do seu estado efetuada pela reflexão deve ser considerada 
uma mudança do sujeito que permanece numericamente idêntico e, assim, deve ser concebida de acordo com o conceito moderado de identidade. ${ }^{18}$

Além de ser fundada na concepção moderada da identidade do sujeito, a dedução transcendental das categorias pressupõe, segundo Henrich, uma certa noção do estatuto epistemológico da consciência dessa identidade. $\mathrm{Na}$ passagem supracitada em A 108 - a passagem chave para Henrich -, Kant enfatiza que o sujeito pensa a sua identidade a priori. Essa certeza cartesiana da consciência de si é uma premissa independente da tese de que a identidade do sujeito deve ser concebida como identidade numérica moderada. Segundo Henrich, o status apriorístico é igualmente constitutivo para a questão sistemática da dedução das categorias, a saber: como é possível para um sujeito ser a priori consciente da sua identidade numérica em todos os seus estados representacionais? Compreende-se o argumento da dedução das categorias ao se reconstruir a melhor resposta a essa pergunta que pode ser dada dentro do quadro teórico kantiano.

\section{Relação entre identidade e objetividade}

É necessário conceber a dedução das categorias como um argumento que está fundado tanto na identidade moderada da consciência de si como na aprioridade de sua certeza, enquanto duas premissas independentes. $\mathrm{O}$ sujeito tem consciência de si com certeza cartesiana e essa certeza contém a consciência de sua identidade numérica. Assim, tudo que está implicado no pensamento da identidade numérica, e que constitui seu significado, deve estar envolvido no conhecimento a priori que o sujeito tem de si. No entanto, a identidade implica uma seqüência de estados do mesmo sujeito. Pois segundo o conceito moderado de identidade numérica, é apenas na passagem de um estado a outro que o sujeito pode ser o mesmo. Então, o sujeito deve ter um conhecimento, anteriormente a toda experiência, do que significa passar de um estado de representação a outro.

Segundo a reconstrução feita por Henrich, é neste ponto que o conceito de regra entra na argumentação kantiana. ${ }^{19} \mathrm{O}$ conhecimento a priori da própria identidade deve incluir alguma concepção da maneira pela qual se passa de um estado para um outro. Sem isso, a consciência a priori de que a própria identidade sofre alterações de estado não teria conteúdo. Então, a consciência da própria identidade inclui um conhecimento a priori de certos modos de passagem ou transição. No entanto, esse conhecimento deve ser considerado 
um conhecimento a priori de regras de acordo com as quais as passagens são feitas. Uma regra é a maneira pela qual ações são exercidas. Com esse passo estabelece-se uma conexão intrínseca entre consciência de si e conhecimento de regras a priori. E exatamente essa conexão é fundamental para formular a tese de que a consciência de si torna necessária a referência a objetos.

A conexão do resultado estabelecido com a análise de objetividade torna-se evidente se reconhecermos que regras a priori para a passagem de um estado a outro são, quanto aos conteúdos conscientes nesses estados, regras a priori da síntese desses estados. Pois a síntese de acordo com regras a priori mostrouse necessária para a referência a objetos na análise kantiana de objetividade. Então, conclui Henrich, o argumento kantiano que investiga as condições da consciência que o sujeito tem a priori de sua identidade numérica realmente é capaz de estabelecer que a referência a objetos é necessária para a consciência de si. Esse argumento depende essencialmente do conceito moderado de identidade numérica, e da pressuposição da aprioridade da consciência que o sujeito tem da sua identidade.

Como Henrich observa, Kant não distingue claramente na dedução das categorias entre a simplicidade e a identidade. Há, em Kant, uma associação não-refletida das duas argumentações. Segundo Henrich, essa associação não é sem fundamento: pode-se conceber a dedução das categorias como uma combinação dessas duas argumentações, a saber, como uma argumentação que parte da unidade que está envolvida na simplicidade e que, ao acrescentar a condição de identidade, mostra que essa unidade deve ser concebida com relação às passagens conscientes que a identidade - da qual o sujeito possui consciência a priori - envolve. O segundo passo aprofunda a concepção de unidade introduzida pela concepção de simplicidade de tal maneira que regras da síntese conhecidas a priori mostram-se envolvidas na unidade dos conteúdos que a consciência de si implica. ${ }^{20}$

$20 \mathrm{HENRICH}$, p. 94 et seq. A argumentação esboçada acima ainda não estabelece regras específicas de acordo com as quais a síntese deve ser exercida. A respeito desse ponto, Henrich (1976) observa que a dedução só fornece condições por um sistema de regras sem especificar quais seriam essas regras; o sistema exigiria referência às formas do juízo como premissa independente (ver HENRICH, 1976, p. 105). No entanto, em Henrich (1988) expõem-se as três regras correspondentes às categorias da relação como implicações da concepção de um sistema de regras a priori da passagem, acrescentando, assim, ao argumento de 1976 uma justificação de regras específicas que é independente da referência às formas do juízo (ver HENRICH, 1988, p. 65-66). 


\section{O aspecto jurídico da dedução: legitimação por um "fato"}

\section{O pano de fundo jurídico do conceito kantiano de "dedução"}

A análise da estrutura da dedução, assim como da relação entre o princípio de identidade da consciência de si e a referência a objetos na dedução, constituem a base para Henrich se dedicar então a uma questão fundamental: a relação entre legitimação e fato. Henrich elucida esta relação em seu artigo "Kant's Notion of the Deduction" (1989), investigando a metodologia da argumentação kantiana. Aqui, ele observa que, como a dedução transcendental da primeira Crítica não é a única, a interpretação dela deve ser compatível com a da dedução transcendental da liberdade na segunda Crítica, que depende de um "fato da razão". Portanto, uma interpretação da dedução transcendental da primeira Crítica só será bem sucedida se for capaz de mostrar que - e como - uma dedução transcendental pode se referir a um fato (apesar de que opomos esses dois conceitos, validade e fato, quase que automaticamente).

Para isso, Henrich investiga a metodologia da dedução transcendental a partir do próprio sentido do termo "dedução". ${ }^{21}$ Entendemos dedução como o procedimento lógico pelo qual uma proposição - a conclusão - é formulada a partir de sua relação formal com outras proposições - suas premissas. Contudo, observa Henrich, este não é o único uso do termo, nem o mais comum na linguagem acadêmica do século XVIII. O significado em que Kant usa o termo é explicado na primeira frase do tópico "Os princípios de qualquer dedução transcendental" na primeira Crítica: "Juristas, falando de direitos e usurpações, distinguem na ação legal a questão de direito (quid iuris) da questão de fato (quid facti); e pedem que ambas sejam provadas. A prova da primeira, que tem de definir o direito ou a pretensão legal, é chamada por eles de dedução" (A 84/B 116). Pensar que Kant usa dedução em sentido lógico, esquecendo-se desta referência jurídica, é o que leva a interpretações equívocas.

Mas por que Kant adota o termo dedução a partir de seu contexto jurídico, transferindo-o para seu programa filosófico? Henrich procura responder a essa questão analisando a forma argumentativa de uma dedução jurídica, que parte da divisão básica do direito em direitos inatos e direitos adquiridos. ${ }^{22}$ Os direitos inatos são inseparáveis do ser humano enquanto tal. Já os direitos adquiridos têm uma origem particular em um fato. Por exemplo, posso ter 
um título nobiliárquico se sou o filho legítimo de um certo casal; posso ter um título acadêmico se passei em certos exames; posso ser proprietário de um bem se o adquiri por meios legais. Para decidir se um direito adquirido é verdadeiro ou apenas presumido, deve-se explicar sua origem, que é um fato (o fato de algo ter sido adquirido, por exemplo, mediante compra ou herança). É a esta origem factual que a dedução remonta. A tese fundamental de Henrich é que há para Kant uma analogia muita estreita entre a argumentação jurídica e os argumentos fundamentais da filosofia crítica, que incluem também a referência essencial a um fato legitimador. Então, ao referir-se à dedução jurídica na primeira Crítica, Kant diz algo muito significativo sobre a estrutura da sua argumentação. A questão "como é possível..." pergunta pela origem do uso dos conceitos puros do entendimento, uma origem que deve ser um fato possuindo força legitimadora. ${ }^{23}$

Contudo, isso não confundiria a questão de direito e a questão de fato? Ora, é preciso levar em conta que ambas essas questões buscam uma compreensão da origem, mas cada uma por seu próprio meio. Por exemplo, no caso de uma transferência de propriedade por testamento, a questão de direito refere-se a um fato fundamental: a origem da propriedade provém de um testamento cuja vontade é autêntica e válida. A questão de fato preocupase em narrar como o testamento foi concebido, escrito e preservado - ou seja, refere-se a fatos circundantes. Mesmo que não se possa produzir a história do testamento - a questão de fato -, a questão de direito pode ser determinada na corte de maneira decisiva. Segundo Henrich, o mesmo pode ser aplicado para a dedução transcendental das categorias. Deduções não podem prescindir de referência a fatos a partir dos quais nosso conhecimento se origina. Assim, a consciência que nós, enquanto sujeitos pensantes, temos da própria identidade, e a consciência da unidade de tempo e espaço são tais fatos aos quais a dedução transcendental das categorias se refere. Não é preciso compreender exaustivamente a gênese e a constituição desses fatos, mas apenas aspectos que sejam suficientes para justificar as pretensões de nosso conhecimento.

\section{A metodologia da dedução}

Foi já visto que o objetivo da dedução é justificar o direito de usar as categorias, apelando a traços particulares da origem do seu uso. Compreendido o programa implicado na noção de dedução, cabe agora entender a metodologia de Kant. Isso é fundamental para se compreender como é possível que a dedução

23 As questões decorrentes da transferência do conceito de "fato" para o contexto transcendental serão discutidas na quarta parte deste trabalho. 
remeta a fatos. ${ }^{24}$ Segundo Henrich, é decisivo aqui considerar a distinção entre reflexão (reflexio) e investigação (examinatio) que Kant introduziu em suas aulas do início da década de 80. Essa distinção baseia-se nos seguintes aspectos: (a) nossas capacidades cognitivas formam uma teia, não podendo ser reduzidas a uma única forma de operação inteligente fundamental; (b) cada uma destas capacidades se torna operativa espontaneamente em seu domínio; (c) para ter conhecimento verdadeiro, cada operação deve se manter nos limites de seu domínio. A reflexão é o conhecimento que a mente implicitamente tem das suas operações e dos princípios dessas operações. Ela acompanha toda atividade epistêmica; em virtude da reflexão, a mente conhece que tipo de atividade está exercendo (por exemplo, analisar e não sintetizar, calcular e não contar). Esse conhecimento está intrinsecamente envolvido no exercício da mesma atividade. Não é, contudo, um conhecimento exaustivo dos processos e operações do conhecimento, mas apenas uma noção dos princípios gerais nos quais se funda a atividade que está sendo exercida.

Em contraste com a reflexão, a investigação é uma atividade deliberada da mente, que torna suas operações objeto da consideração explícita. A Crítica (e sua dedução) é uma investigação sobre pretensões de conhecimento. Ela detecta conexões e liga princípios que orientam um discurso para os fatos e as operações fundamentais que o constituem, podendo ainda interpretá-los e validá-los. Segundo Henrich, entender a relação da investigação com a reflexão é decisivo para compreender a metodologia da dedução transcendental: a investigação funda-se na reflexão, no conhecimento implícito das suas operações e dos princípios dessas operações que a mente possui. Ela torna esse conhecimento um conhecimento explícito, mas ainda parcial, desses princípios, compreendendo as relações legitimadoras que existem entre eles.

Os dois corolários disso são: primeiro, toda dedução, como investigação, deve repousar sobre argumentos que se referem diretamente ao que é revelado pela reflexão. Sua característica formal é o esclarecimento da consciência de que uma operação particular depende de outra ainda mais fundamental. Assim, ela mostra que a análise é sempre acompanhada de sínteses em um nível mais profundo, e que a síntese, por sua vez, requer princípios de unidade que não se originam na experiência. O segundo corolário disso é que Kant não explicita sua metodologia filosófica. A questão é: como transformar um conhecimento implícito em conhecimento explícito? Para isso, Kant formulou sua teoria dos "juízos preliminares" (judicia praevia), resultado da tendência que surge na 
reflexão de conceituar nossas faculdades cognitivas. A investigação começa a partir destes juízos preliminares - mesmo que não sejam aceitos. Em suas aulas sobre Lógica, contudo, Kant diz que temos apenas uma compreensão rudimentar desse mecanismo.

A última consideração de Dieter Henrich sobre a metodologia kantiana revela uma importante aplicação de sua doutrina sobre o papel da distinção entre reflexão e investigação filosófica. A noção chave da dedução na primeira Crítica é a unidade da apercepção, a qual Kant se refere como o "eu penso". O "eu penso", observa Henrich, é a consciência de si que pode acompanhar toda reflexão, independentemente do tipo de atividade cognitiva ao qual ela se refere. Isso sugere que o princípio pelo qual a dedução mais fundamental deve ser desenvolvida possui a generalidade e o âmbito irrestrito que é o traço fundamental do processo de reflexão sobre o qual se baseia continuamente o método de justificação ou investigação filosófica. Daí a relação entre a noção chave da dedução na Crítica e o princípio metodológico de todas as deduções, a correlação entre reflexão e investigação.

\section{O conceito de "fato" no contexto transcendental: implicações e uma dúvida}

Henrich tem o mérito de reconstruir detalhadamente o argumento kantiano esclarecendo, ao mesmo tempo, o pano de fundo de sua metodologia. O núcleo do projeto da dedução transcendental, na sua reconstrução, é a concepção de princípios conhecidos pela reflexão que subjazem a nosso discurso, possuindo - em correspondência ao conceito jurídico de dedução - o status de fatos legitimadores. No entanto, isso levanta a seguinte questão: em que medida a concepção de "fatos legitimadores" pode ser transferida do seu contexto original jurídico para o contexto bem diferente da legitimação transcendental? Os conceitos de "fato" nos dois contextos não são idênticos; pode-se apenas dizer que sejam análogos. No contexto jurídico, "fatos" são acontecimentos confirmados por documentos ou depoimentos. No entanto, os princípios das deduções filosóficas são qualificados de "fatos" por serem princípios constitutivos para nossa perspectiva epistêmica sem que possam ser comprovados como necessários para toda prática cognitiva como tal. No contexto filosófico, o caráter factual dos respectivos princípios significa que não é possível derivá-los a partir de condições epistêmicas mais fundamentais.

Mostra-se assim claramente que Henrich reconstrói a dedução transcendental de modo absolutamente oposto ao de P. F. Strawson, que 
combina elementos da filosofia crítica e da filosofia analítica. ${ }^{25}$ Para Strawson, a dedução transcendental tem por intuito refutar o empirismo cético de cunho humiano. O sucesso desse projeto depende de que a argumentação se baseie em um pressuposto também aceito pelo cético. Strawson sugeriu, por isso, reconstruir a dedução transcendental das categorias a partir de uma concepção mínima da experiência que não envolve mais do que a condição de que conceitos são aplicados a conteúdos particulares de intuições. As condições introduzidas explicitamente por Kant como princípios da dedução transcendental - em particular, a consciência "Eu penso" - evidenciam-se, segundo Strawson, como implicações necessárias da concepção mínima da experiência. Assim, elas não são "fatos" últimos, mas implicações analíticas do conceito de experiência no sentido mínimo aceito também pelo cético humiano. Não surpreende, portanto, que Strawson coloque em dúvida o caráter factual dos respectivos princípios ao comentar a contribuição de Henrich acerca da metodologia kantiana, defendendo a possibilidade de inferi-los a partir de condições mais fundamentais, envolvidas no conceito mínimo de experiência. ${ }^{26}$

O mérito de Strawson é mostrar como a dedução kantiana pode ser entendida como um argumento que reduz ao absurdo o empirismo humiano. No entanto, sua reconstrução envolve consideráveis problemas internos. Tem-se contestado particularmente a passagem da concepção mínima da experiência para o "Eu penso" como condição da experiência. Assim, numa abordagem detalhada acerca da estrutura da dedução das categorias, R. Howell negou que se possa evidenciar a consciência de si como implicação analítica da concepção mínima de experiência, isto é, como necessária para qualquer consciência conceitual de dados singulares. Mesmo se o passo da identidade do "Eu penso" para a necessidade do uso das categorias fosse válido, segundo Howell o argumento não refuta cogentemente o cético humiano, que insiste na imagem da experiência como sequiência de dados sem referência a objetos e à identidade do "eu", situando estes no domínio das ilusões filosóficas. ${ }^{27}$

O resultado negativo de que os princípios explícitos da dedução das categorias não podem ser inferidos de uma concepção mínima de experiência como exigido na reconstrução de Strawson - pode ser visto como confirmação do seu caráter "factual". No entanto, esse resultado também gera um impasse a respeito da crítica de Kant a Hume. Pois na imagem da experiência adotada por 
Hume os princípios da dedução transcendental - em particular, a identidade do "Eu penso" - não estão incluídos; por isso parecia necessário derivá-los de um conceito de experiência aceito também pelo cético, e assim levar sua posição ao absurdo. A reconstrução de Henrich exclui essa estratégia. Em vez disso, o argumento da dedução parece só poder apelar para a consciência dos respectivos princípios como condições fundamentais de nosso conhecimento, embora ignorados pelo empirista humiano. Tal é o papel da reflexão e sua evidência, no sentido proposto por Henrich. Assim, desde o início, o argumento kantiano pressupõe um ponto de vista diferente da visão humiana da experiência - ele pressupõe o reconhecimento de condições não aceitas por esta, e também não dedutíveis de uma concepção mais fundamental.

Em comparação com o projeto da dedução na sua reconstrução analítica, isso significa um enfraquecimento com respeito a seu propósito. Em vez de refutar a posição de Hume, a partir de suas próprias premissas, o argumento da dedução pressupõe, na interpretação de Henrich, uma perspectiva oposta a esta, que não pode ser defendida por argumentos, mas se baseia na evidência de uma reflexão pré-filosófica e inerente ao discurso comum. Por conseguinte, a função da dedução transcendental consistiria em evidenciar a objetividade, enquanto possibilitada por princípios a priori, como um momento necessário dessa perspectiva. A dedução transcendental revela as implicações da perspectiva interna para a qual ela apela.

Com essa implicação da interpretação defendida por Henrich, desenhase mais claramente o perfil do projeto filosófico que ela envolve. No entanto, mostram-se aqui também os limites da analogia entre "fatos" no sentido jurídico e no sentido da dedução transcendental. O jurista tem que demonstrar objetivamente seus enunciados sobre os fatos relevantes acerca da origem da posse (o que acontece por meio de documentos e depoimentos). Contudo, a dedução transcendental só pode apelar para um certo ponto de vista - a perspectiva não-humiana da "reflexão - para fazer valer seus "fatos" legitimadores. Assim, não surpreende que a concepção do apelo para um "ponto de vista" fundamental para a filosofia transcendental tenha se tornado central para a discussão metodológica já pouco tempo depois da publicação da Crítica da Razão Pura. Nessa discussão, a caracterização dos princípios da filosofia transcendental pelo conceito de "fato" logo pareceu duvidosa. ${ }^{28} \mathrm{Sem}$

28 Ver o terceiro volume do Resumo explicativo dos escritos críticos do senhor prof. Kant, de J.S. Beck, que trata do "ponto de vista" pressuposto pela filosofia transcendental (BECK, 1796). A concepção do apelo para o ponto de vista da nossa atividade epistêmica, defendida por ele, foi adotada por Fichte na segunda exposição dos fundamentos do seu sistema, a chamada "Doutrina da Ciência nova methodo" (FICHTE, 1982). 
dúvida, a interpretação feita por Henrich acerca da dedução transcendental coloca em foco um aspecto decisivo para a compreensão do argumento; no entanto, as diferenças entre o contexto jurídico a partir do qual Kant introduziu sua concepção metodológica, e o contexto filosófico-transcendental, devem ser devidamente consideradas, a fim de que se especifique em que medida o conceito de "fato" é capaz de elucidar o status dos princípios da dedução transcendental.

\section{Referências Bibliográficas}

ADICKES, Erich. Kants Kritik der reinen Vernunft. Berlin: Mayer \& Müller, 1889. BECK, Jacob S. Erläuternder Auszug aus den critischen Schriften des Herrn Prof. Kant. Dritter Band, welcher den Standpunkt darstellt, aus welchem die critischen Philosophie zu beurteilen ist. Riga, 1796.

ERDMANN, Benno. Kants Kriticismus in der 1. und 2. Auflage der Kritik der reinen Vernunft. Leipzig: Voss, 1878.

FICHTE, Johann G. Wissenschaftslehre nova methodo. Herausg. E. Fuchs. Hamburg: Meiner, 1982.

HENRICH, Dieter. Die Beweisstruktur von Kants Transzendentaler Deduktion. In: PRAUSS, Gerold (Ed.). Kant. Zur Deutung seiner Theorie von Erkennen und Handeln. Köln: Kiepenheuer und Witsch, 1973. p. 90-104.

HENRICH, Dieter. Identität und Objektivität. Eine Untersuchung über Kants transzendentale Deduktion. Heidelberg: Winter, 1976.

HENRICH, Dieter. Die Identität des Subjekts in der transzendentalen Deduktion. In: OBERER, Hariolf; SEEL, Gerhard (Ed.). Kant: Analysen - Probleme - Kritik. Würzburg: Könighausen \& Neumann, 1988. p. 39-70.

HENRICH, Dieter. Kant's Notion of the Deduction. In: FÖRSTER, Eckart. Kant's Transcendental Deductions. The three "Critiques" and the "Opus Posthumum". Stanford: Stanford University Press, 1989. p. 29-46.

HENRICH, Dieter. Grundlegung aus dem Ich. Untersuchungen zur Vorgeschichte des Idealismus. Frankfurt a. M.: Suhrkamp, 2004.

HOWELL, Thomas C. Kant's Transcendental Deduction. An Analysis of Main Themes in His Critical Philosophy. Dordrecht/Boston: Kluwer, 1992.

KANT, Immanuel. Kritik der reinen Vernunft. (1787 [1781]). In: PREUSSISCHE AKADEMIE DER WISSENSCHAFTEN (Ed.). Kantswerke. Berlin: Walter de Gruyter, 1904. v. 3.

KANT, Immanuel. Kritik der praktischen Vernunft. [1788]. In: PREUSSISCHE AKADEMIE DER WISSENSCHAFTEN (Ed.). Kantswerke. Berlin: Walter de Gruyter, 1908. v. 5.

PATON, Herbert James. Kant's Metaphysic of Experience. London: Allen \& Unwin, 1936. v. 1, p. 501. 
SMITH, Norman Kemp. Tradução de KANT, Immanuel. Critique of Pure Reason. New York: St. Martin's, 1965.

STRAWSON, Peter F. The Bounds of Sense. London: Methuen, 1966.

STRAWSON, Peter F. Sensibility, Understanding, and the Doctrine of Synthesis:

Comments on Henrich and Guyer. In: FÖRSTER, Eckart. Kant's Transcendental Deductions. The three "Critiques" and the "Opus Posthumum". Stanford: Stanford University Press, 1989. p. 69-77.

VLEESCHAUWER, Herman de. La déduction transcendentale dans l'œuvre de Kant. In: Recueil de travaux. Antwerpen: De Sikkel, 1937. v. 3. 